\title{
Lymphocytes genetically modified to express tumor antigens target DCs in vivo and induce antitumor immunity
}

\author{
Vincenzo Russo, ${ }^{1}$ Arcadi Cipponi, ${ }^{1}$ Laura Raccosta, ${ }^{1}$ Cristina Rainelli, ${ }^{1}$ Raffaella Fontana, ${ }^{1}$ \\ Daniela Maggioni, ${ }^{1}$ Francesca Lunghi, ${ }^{2}$ Sylvain Mukenge, ${ }^{3}$ Fabio Ciceri, ${ }^{2}$ Marco Bregni, ${ }^{4}$ \\ Claudio Bordignon, ${ }^{1,2,5,6}$ and Catia Traversari ${ }^{6}$
}

\begin{abstract}
${ }^{1}$ Cancer Gene Therapy Unit, Cancer Immunotherapy and Gene Therapy Program, ${ }^{2}$ Bone Marrow Transplantation Unit, ${ }^{3}$ Department of Surgery, and ${ }^{4}$ Strategic Program of Oncology, Scientific Institute H. San Raffaele, Milan, Italy. ${ }^{5}$ Università Vita-Salute San Raffaele, Milan, Italy. ${ }^{6}$ MolMed S.p.A., Milan, Italy.
\end{abstract}

\begin{abstract}
The exploitation of the physiologic processing and presenting machinery of DCs by in vivo loading of tumorassociated antigens may improve the immunogenic potential and clinical efficacy of DC-based cancer vaccines. Here we show that lymphocytes genetically modified to express self/tumor antigens, acting as antigen carriers, efficiently target DCs in vivo in tumor-bearing mice. The infusion of tyrosinase-related protein 2 -transduced (TRP-2-transduced) lymphocytes induced the establishment of protective immunity and long-term memory in tumor-bearing mice. Analysis of the mechanism responsible for the induction of such an immune response allowed us to demonstrate that cross-presentation of the antigen mediated by the CD11c $c^{+} C D 8 \alpha^{+} D C$ subset had occurred. Furthermore, we demonstrated in vivo and in vitro that DCs had undergone activation upon phagocytosis of genetically modified lymphocytes, a process mediated by a cell-to-cell contact mechanism independent of CD40 triggering. Targeting and activation of secondary lymphoid organ-resident DCs endowed antigen-specific $T$ cells with full effector functions, which ultimately increased tumor growth control and animal survival in a therapeutic tumor setting. We conclude that the use of transduced lymphocytes represents an efficient method for the in vivo loading of tumor-associated antigens on DCs.
\end{abstract}

\section{Introduction}

The identification of genes coding for human tumor-associated antigens (TAAs) (1), the characterization of DCs as the most potent APCs (2), as well as the accumulating evidence refining the concept of tumor immunoediting and immunosurveillance (3) have all renewed interest in the preclinical and clinical aspects of cancer immunotherapy. Indeed, the results of adoptive immunotherapy trials in both solid $(4,5)$ and hematologic $(6,7)$ malignancies confirm that immune effectors represent potent anticancer agents and their use may result in clearance of tumor cells. These results suggest that a suboptimal induction phase could be one of the factors responsible for the limited clinical efficacy of most vaccination trials (8). On the other hand, a large variety of immune escape mechanisms adopted by tumors (i.e., the secretion of immunesuppressive factors by large tumor masses, the generation of TAAs and/or HLA loss variants, induction of TAA-specific tolerance by the tumor, and the intrinsic low immunogenicity of several tumor antigens; refs. 9, 10) as well as heavy pretreatments of the patient could limit the efficacy of anticancer vaccines (11). Novel strategies of active vaccination should consider all these aspects in order to become effective.

At present, a major role in eliciting $\mathrm{T}$ cell priming is conferred to secondary lymphoid organ-resident (SLO-resident) DCs $(12,13)$. This suggests that the next generation of DC-based vaccines should

Nonstandard abbreviations used: B6, C57BL/6 (mice); CSM, cell-surface marker; DT, diphtheria toxin; GML, genetically modified lymphocyte; $\triangle \mathrm{LNGFr}$, truncated low-affinity nerve growth factor receptor; PI, propidium iodide; SLO, secondary lymphoid organ; TAA, tumor-associated antigen; TRP-2, tyrosinase-related protein 2. Conflict of interest: The authors have declared that no conflict of interest exists. Citation for this article: J. Clin. Invest. 117:3087-3096 (2007). doi:10.1172/JCI30605 target DCs in vivo, thus exploiting their physiological immunostimulatory capabilities. Indeed, promising results have been obtained in murine tumor models by in vivo targeting of SLO-resident DCs with antigen conjugated to DC-specific mAb (14).

Defined subsets of $\mathrm{T}$ lymphocytes are known to be able to migrate to SLOs (15) and to induce a Th-independent cytolytic $\mathrm{T}$ cell response in vitro (16). Additionally, we and others have recently shown that, in clinical settings of allogeneic bone marrow transplantation, genetically modified lymphocytes (GMLs) can induce a highly specific immune response against the transgene products (i.e., herpes simplex virus thymidine kinase [HSV-TK]) when injected into immunocompetent patients $(6,17,18)$.

This evidence represents the experimental observation at the basis of our novel vaccination approach. In murine models, we showed that transduced lymphocytes, delivering antigens to host DCs located in SLOs, elicit protective immunity and long-term memory in tumor-bearing mice by cross-presentation.

\section{Results}

GMLs expressing the self/tumor antigen tyrosinase-related protein 2 are able to induce tumor-specific immune responses, ultimately controlling the growth of B16F1 melanoma. We and others have obtained evidence that the in vivo administration of HSV-TK-transduced allogeneic lymphocytes, used as donor lymphocyte infusions in clinical trials of allogeneic bone marrow transplantation, could specifically prime the recipient immune system in a vaccine-like mode, inducing TK-specific T cell effectors $(6,17,18)$. This unexpected result prompted us to investigate whether lymphocytes genetically modified to express a self/tumor antigen (TAA) were indeed able to elicit TAA-specific effectors. To address this issue, we used the murine self/tumor antigen TRP-2, expressed by normal mela- 


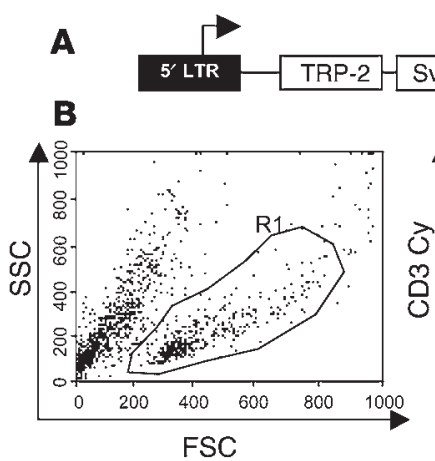

C
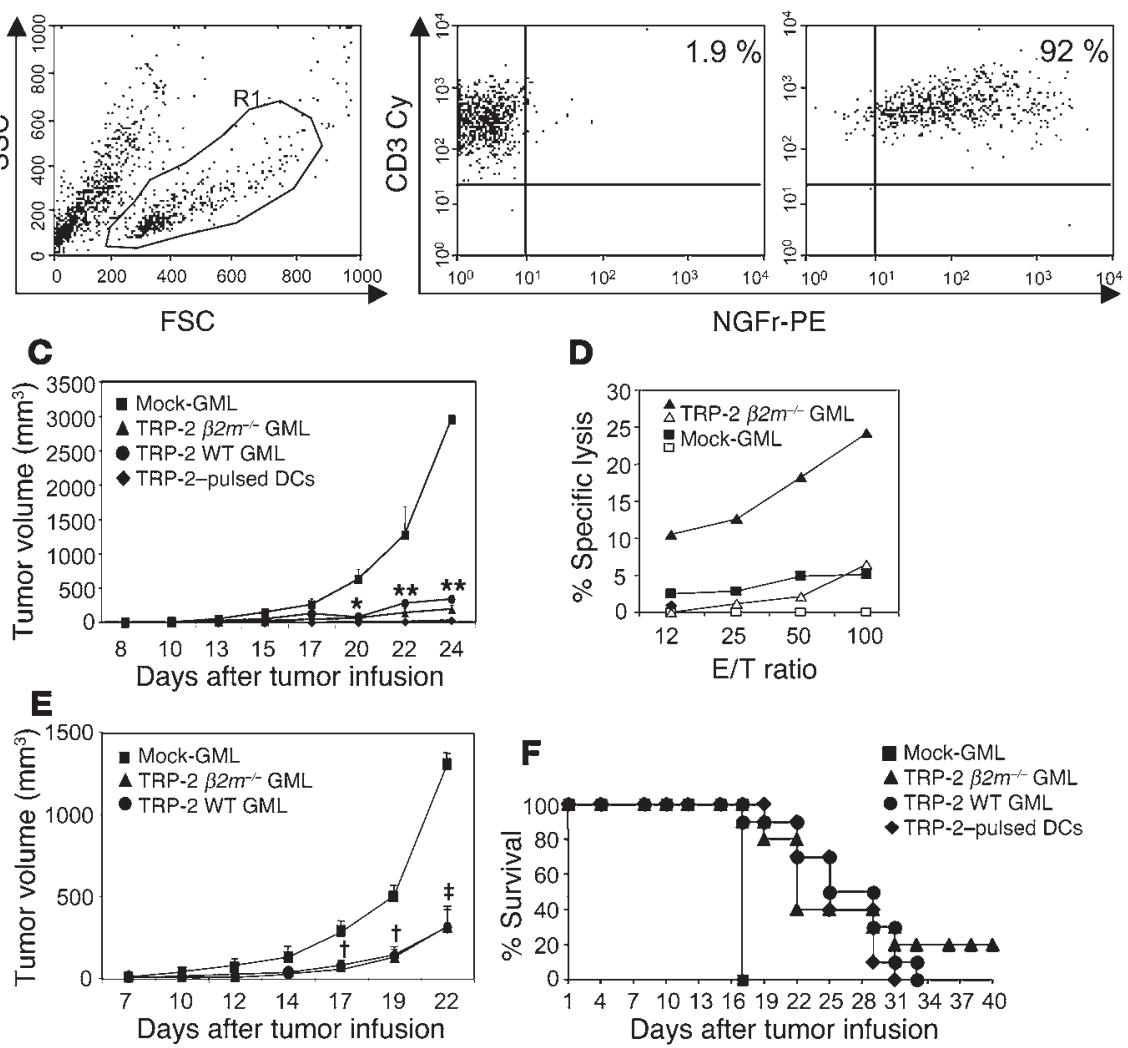

D
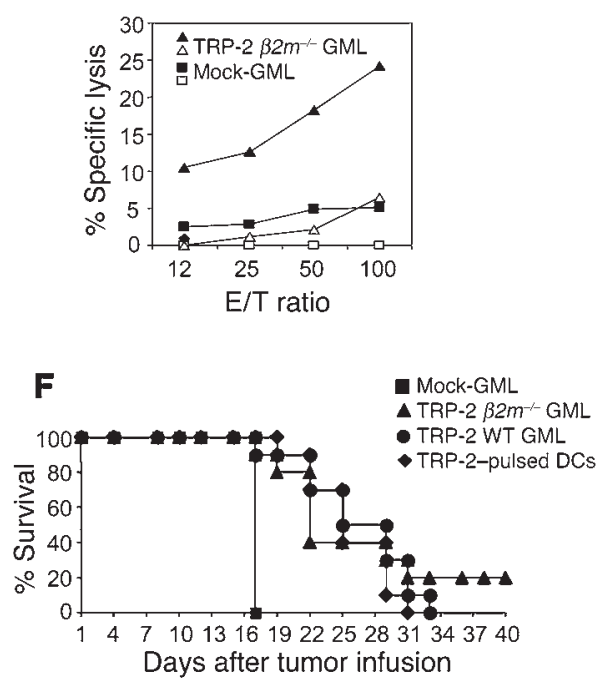

Figure 1

Infusion of TRP-2-GMLs protects mice from tumor challenge, induces memory responses, and prolongs survival of tumor-bearing mice. (A) B6 splenocytes were transduced with the retroviral vector TRP-2-CSM encoding TRP-2 and the $\Delta$ LNGFr marker. (B) Transduction efficiency. Ninety percent of $\mathrm{CD}^{+}$cells (middle and right panels) expressed $\Delta \mathrm{LNGFr}$ (right panel). Mock-transduced splenocytes were negative (middle panel). (C) B6 mice were treated with mock-transduced GMLs; TRP-2-GMLs from WT (TRP-2 WT) or $\beta 2 m^{-/}$mice (TRP-2 $\beta 2 m^{-/}$); or DCs pulsed with 2 TRP-2 peptides (TRP-2-pulsed DCs). TRP-2-GMLs from both WT and $\beta 2 m^{-/-}$mice were able to control tumor growth. ${ }^{\star} P=0.03$, ${ }^{\star *} P<0.05$; Student's $t$ test. (D) The infusion of TRP-2-GMLs elicits TRP-2-specific cytotoxic T cells. Splenocytes from vaccinated mice were restimulated in vitro with TRP-2 peptides and tested in a cytotoxicity assay against pulsed (filled symbols) or unpulsed (open symbols) RMA cells. (E) Induction of memory antitumor responses. Forty days after vaccination, B16 cells were implanted s.c. TRP-2-GMLs from both WT and $\beta 2 \mathrm{~m}^{-/-}$mice were able to control tumor growth. ${ }^{\dagger} P<0.005,{ }^{\ddagger} P<0.0005$; Student's $t$ test. Data shown in $\mathbf{C}$ and $\mathbf{E}$ are representative of 2 experiments with 5 mice/group. (F) KaplanMeier survival graphs. Mice were treated as described in Methods. Statistical comparison of the survival curves, performed by the log-rank test, gave the following results: $4 \times 10^{6}$ TRP-2-GMLs versus mock-GMLs, $P<0.005 ; 10 \times 10^{6}$ TRP-2-GMLs versus mock-GMLs, $P<0.005$; TRP-2pulsed DCs versus mock-GMLs, $P<0.005$.

nocytes and by the murine melanoma B16F1 (B16) (19). Splenocytes from WT and $\beta 2 m^{-/-} \mathrm{C} 57 \mathrm{BL} / 6$ (B6) mice were activated and transduced with the TRP-2-CSM retroviral vector, which codes for the TRP-2 tumor antigen and for a cell-surface marker (CSM), the biologically inactive form of the low-affinity nerve growth factor receptor $(\triangle \mathrm{LNGFr})$, for purification and in vivo tracing of the transduced cells (20) (Figure 1A). In a large series of experiments, we obtained homogeneous populations of $\mathrm{CD} 3^{+}$lymphocytes, transduced by $69 \%-90 \%$, evaluated as $\Delta \mathrm{LNGFr}^{+}$cells by FACS analysis at day 10 of culture (Figure $1 \mathrm{~B}$ ). Before the infusion, we measured the rate of apoptosis in the GML populations and found $6 \% \pm 2.4 \%$ of cells to be in early apoptosis (annexin $\mathrm{V}^{+}$/propidium iodide ${ }^{-}$[annexin $\left.\left.\mathrm{V}^{+} / \mathrm{PI}^{-}\right]\right), 15.7 \% \pm 0.9 \%$ of cells in late apoptosis/secondary necrosis $\left(\right.$ annexin $\left.\mathrm{V}^{+} / \mathrm{PI}^{+}\right)$, and only $0.45 \% \pm 0.5 \%$ in necrosis (annexin $\mathrm{V}^{-} / \mathrm{PI}^{+}$). The vast majority of the cells $(75 \% \pm 3.1 \%)$ were annexin $\mathrm{V}^{-} / \mathrm{PI}^{-}$viable cells. Transduced cells $\left(4 \times 10^{6}\right)$ were then injected i.v. in B6 mice, 3 times at 2 -week intervals. Two weeks after the last infusion, B16 melanoma cells were given s.c. Mice treated with mock-transduced GMLs (mock-GMLs) progressively developed melanoma (Figure $1 C$, squares), whereas mice vaccinated with TRP-2-transduced GMLs (TRP-2-GMLs) from WT animals (circles) controlled tumor growth as efficiently as mice treated with DCs pulsed with two TRP-2-derived peptides (diamonds). The vaccination elicited $\mathrm{T}$ cell effectors specific for the TRP-2 tumor antigen. Indeed, following in vitro stimulation with the TRP-2 $181-188$ (19) and TRP-2 ${ }_{180-188}$ (21) peptides, splenocytes from mice vaccinated with TRP-2-GMLs specifically recognized peptide-pulsed RMA cells (Figure 1D). No such cytotoxic $\mathrm{T}$ cells could be established from mice treated with mock-GMLs (Figure 1D). To determine whether $T$ cell priming was mediated by endogenous APCs phagocytosing the antigens released by GMLs, mice were treated with TRP-2-GMLs from $\beta 2 \mathrm{~m}^{-/-}$mice (Figure 1C, triangles). These animals (22) lack MHC class I expression and therefore are unable to present antigens by themselves. The injection of TRP-2-GMLs from $\beta 2 \mathrm{~m}^{-/-}$mice (Figure 1C) controlled melanoma growth similarly to the other conditions, indicating that the induction of the TRP-2-specific immune response would require crosspresentation by host APCs.

This vaccination approach elicited a stable memory response, since mice challenged 40 days after TRP-2-GML vaccination with B16 tumor cells were able to control tumor growth (Figure 1E).

We then asked whether the infusion of TRP-2-GMLs was able to effectively control tumor growth in a therapeutic setting. B6 mice in which B16 tumors had been established for 3 days were injected i.v. 3 times at 7 -day intervals with either $4 \times 10^{6}$ TRP-2-GMLs or $10 \times 10^{6}$ TRP-2-GMLs or with $5 \times 10^{5}$ LPS-activated DCs pulsed with two TRP-2-derived peptides (Figure 1F). We observed a statistically significant prolonged survival in mice treated with TRP-2-GMLs and TRP-2-pulsed DCs. Most importantly, we observed a superior trend of prolonged survival in mice treated with the higher dose of TRP-2GMLs in comparison to those treated with the optimal dose of 

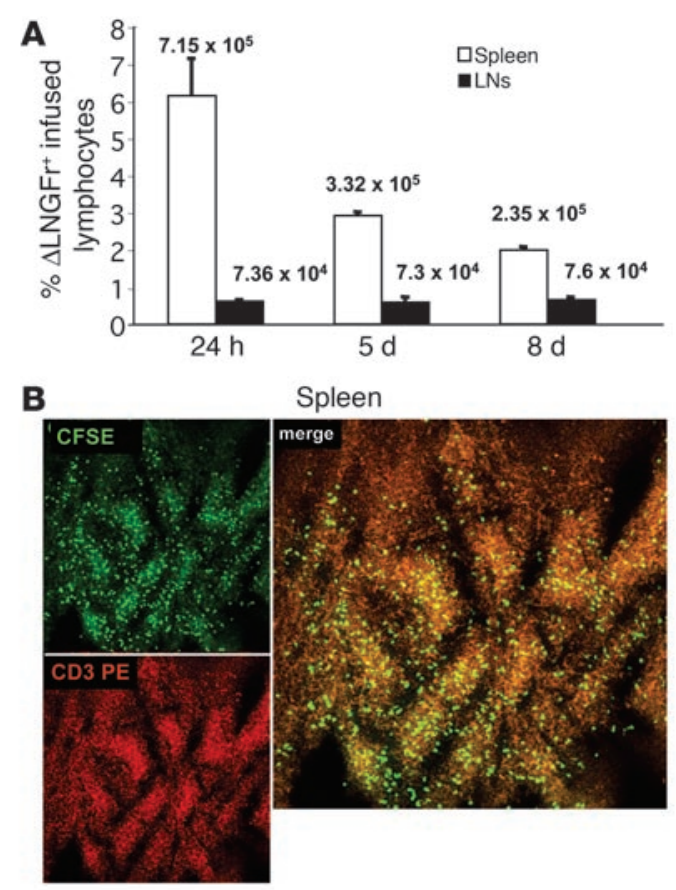

Spleen

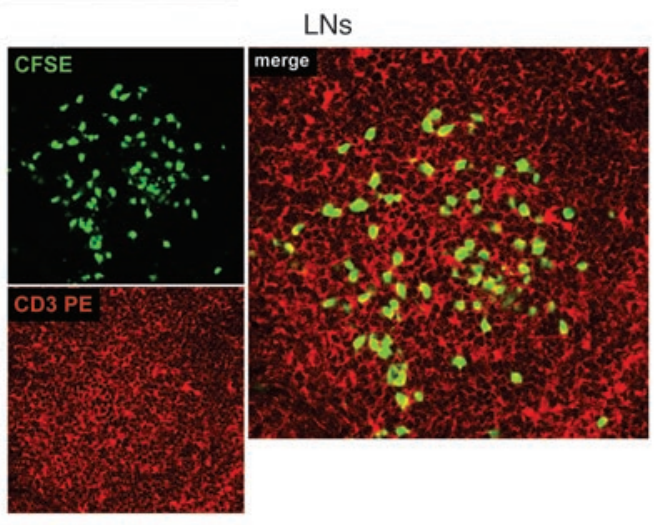

peptide-pulsed DCs. Indeed, $20 \%$ of TRP-2-GML-treated mice were still alive 40 days after tumor infusion.

In vivo migratory ability of GMLs. Priming of immune effector cells occurs in SLOs (23), where professional APCs expressing defined MHC-peptide complexes encounter and activate host naive T cells (2). To investigate the mechanism(s) responsible for the observed immunization, we first verified whether GMLs were indeed able to reach SLOs upon i.v. infusion. GMLs expressing the CSM $\triangle$ LNGFr were infused i.v. into B6 recipients and recovered from SLOs of animals sacrificed at different times. After 24 hours, we detected $6.15 \%$ (corresponding to $7.15 \times 10^{5}$ total cells) of $\triangle \mathrm{LNGFr}^{+} \mathrm{CD}^{+} \mathrm{GMLs}$ within the spleen and $0.61 \%$ (corresponding to $7.36 \times 10^{4}$ total cells) in 5 pooled LNs (Figure 2A). Within the spleen, the number of GMLs slightly decreased over time (Figure 2A), thus suggesting that the GMLs had undergone cell death, a process associated with the release of antigen, and/or recirculation through peripheral tissues. The ability to migrate to SLOs seems to be a feature of GMLs, since we were unable to detect both the lymphoid cell line RMA and the T cell hybridoma TG40 within SLOs of mice injected with comparable or higher numbers of CSFE-labeled RMA and TG40 tumor cells (data not shown). To evaluate the fine localization of

\section{Figure 2}

In vivo homing and persistence of GMLs into SLOs. (A) CFSE-labeled GMLs were injected into naive B6 mice. One, 5, and 8 days after the infusion, we evaluated the presence of $\mathrm{CFSE}^{+}$cells within SLOs by FACS. Numbers reported above the bars indicate the absolute amount of $\mathrm{CFSE}^{+}$cells detected within SLOs of treated mice. Data are representative of at least 4 independent experiments. (B) Serial sections of spleen and LNs were analyzed by confocal microscopy 12 hours after the injection of CFSE-labeled GMLs. CFSE-labeled cells are visualized as green staining, CD3 as red staining. Optically merged confocal images show the colocalization, displayed as yellow staining, of the $\mathrm{CFSE}^{+}$cells with the CD3 marker in both the spleen and the LNs of treated mice. Original magnification, $\times 20$ (spleen); $\times 40(\mathrm{LNs})$.

the GMLs within SLOs, we analyzed serial sections of spleen and LNs from mice injected with CFSE-labeled GMLs. Twelve hours after the infusion, CFSE-GMLs were found in the periarteriolar lymphoid sheaths of the spleen and in the paracortical area of the LNs, interspersed with the endogenous $\mathrm{CD}^{+}$cells (Figure 2B). These experiments clearly demonstrate that a relevant number of GMLs is capable of trafficking through SLOs.

Infusion of OVA-GMLs elicits OVA-specific T cell priming. To dissect the mechanism responsible for GML-mediated T cell priming, we used $\mathrm{T}$ cells derived from the OT-I transgenic line, which carry a transgenic TCR specific for the $\mathrm{H}-2 \mathrm{~K}^{\mathrm{b}}$-pOVA $257-264$ complex, and GMLs transduced with a retroviral vector encoding the model antigen OVA and the CSM $\triangle$ LNGFr (Figure 3A, OVA-CSM vector). As for TRP-2, splenocytes from B6 mice were transduced with the OVA-CSM retroviral vector with an efficiency of $55 \%-90 \%$ (data not shown). We transferred CFSE-labeled, OVA-specific, OT-I CD8 ${ }^{+} \mathrm{T}$ cells into B6 mice and assessed their activation and phenotypic profile 6 days after the infusion of $4 \times 10^{6}$ OVA-transduced or mock-transduced GMLs from either WT or $\beta 2 \mathrm{~m}^{-/-}$mice. In both the experimental settings, FACS analysis of treated mice showed that OT-I T cells had undergone multiple rounds of cell division, evaluated as CFSE dilution, both in LNs (data not shown) and spleen (Figure 3B). Furthermore, proliferating OT-I T cells showed a marked upregulation of CD44, a marker of $\mathrm{T}$ cell activation that is regularly overexpressed upon antigen recognition (24), and downmodulation of the SLO-homing receptor CD62L (Figure $3 \mathrm{~B})$, a function that allows activated effector cells to leave the SLOs and patrol peripheral tissues (24). Finally, we demonstrated that the induced effectors, once restimulated ex vivo with the OVA $257-264$ peptide (SIINFEKL), specifically released IFN- $\gamma$, maintaining the OVA-specific responsiveness (Figure 3C) without undergoing tolerance or anergy (25).

To evaluate whether our strategy would also elicit sizeable endogenous OVA-specific $\mathrm{T}$ cell effectors, we treated mice with OVA-GMLs 3 times at 2-week intervals. Forty days later, spleen and $\mathrm{LNs}$ were harvested and stained with $\mathrm{H}-2 \mathrm{~K}^{\mathrm{b}} / \mathrm{SIINFEKL}$ pentamer and $\mathrm{mAbs}$ specific for $\mathrm{T}$ cell activation and memory markers (Supplemental Figure 1; supplemental material available online with this article; doi:10.1172/JCI30605DS1.). In 2 representative experiments, OVA-GML treatment was able to significantly expand endogenous OVA-specific CD8 ${ }^{+} \mathrm{T}$ cells (Supplemental Figure 1B). In this experimental setting, the OVA-specific $\mathrm{CD}^{+} \mathrm{T}$ cells showed the phenotype of memory cells (Supplemental Figure 1C).

We therefore evaluated whether the vaccination with OVAGMLs was able to induce $\mathrm{CD} 4^{+} \mathrm{T}$ cell responses. We transferred CFSE-labeled, OVA-specific, OT-II CD4 ${ }^{+} \mathrm{T}$ cells into $\mathrm{B} 6$ mice and 

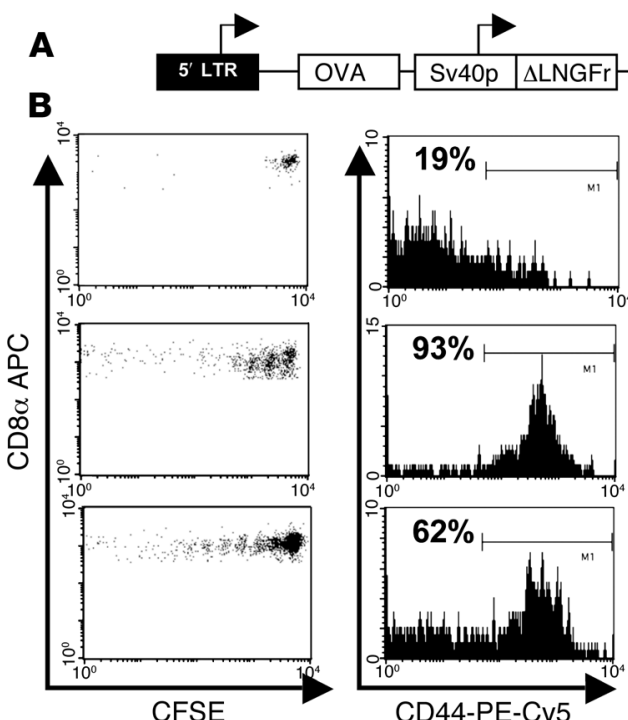

$3^{\prime}$ LTR
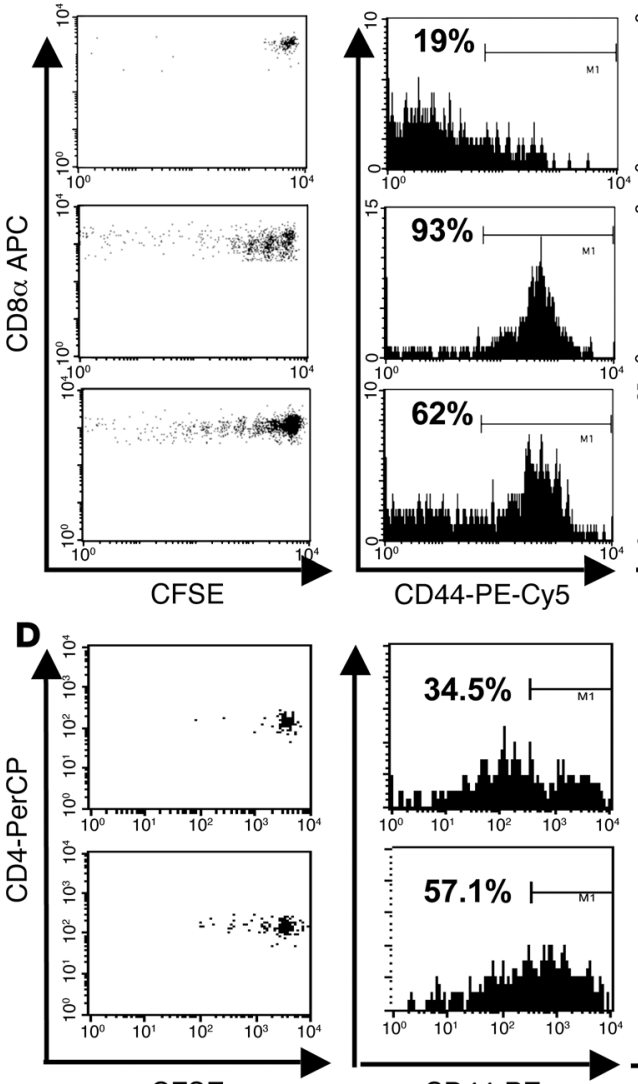

CFSE

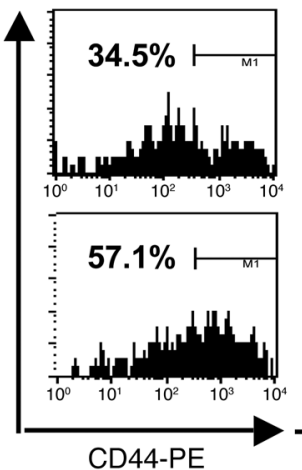

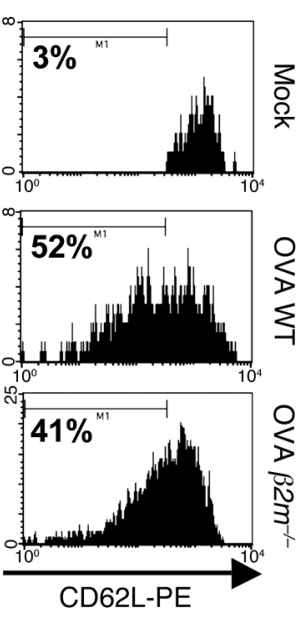

C

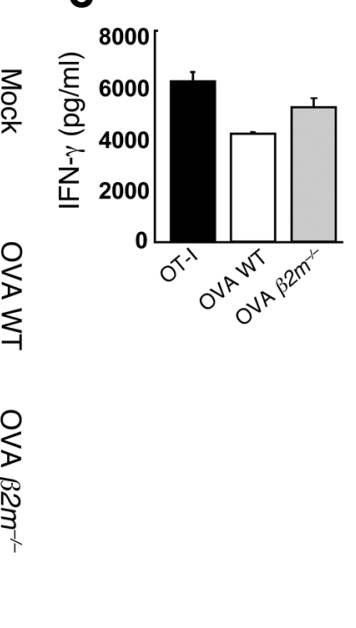

Figure 3

Ex vivo analysis of OT-I and OT-II activation following vaccination with OVA-GMLs. (A) Structure of the retroviral vector OVA-CSM. (B) Twenty-four hours after the infusion of CFSE-labeled OT-I T cells, mice were given mock-GMLs (Mock) or OVA-GMLs from WT (OVA WT) or $\beta 2 \mathrm{~m}^{-/-}\left(\mathrm{OVA} \beta 2 \mathrm{~m}^{-/}\right)$mice. Density dot plots (CFSE, left panels) show OT-I proliferation following treatments. Histograms show the expression of CD44 and downregulation of CD62L. (C) OT-I T cells from treated mice were restimulated

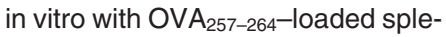
nocytes and tested for IFN- $\gamma$ release against pulsed or unpulsed RMA cells. In vitro-activated OT-I T cells were used as positive control. (D) Twenty-four hours after the infusion of CFSE-labeled OT-II T cells, mice were given mock- or OVA $32 \mathrm{~m}^{-1-}$ GMLs. Density dot plots show OT-II proliferation following treatment with OVA $\beta 2 m^{-/}$GMLs (CFSE, left panels). Histograms show the expression of CD44 and downregulation of CD62L. Data are representative of 3 (B) or 2 (D) experiments performed on splenocytes of 2 mice/group. (E) B16-OVA-bearing mice were transferred with OT-I T cells and then treated with mock- or OVAGMLs from WT or $\beta 2 \mathrm{~m}^{-/-}$mice. ${ }^{*} P<0.05,{ }^{* *} P<0.005$; Student's $t$ test. (F) Mice adoptively transferred with OT-I T cells were challenged with mock- or OVA-GMLs from WT and $\beta 2 \mathrm{~m}^{-/-}$mice. Forty days later, mice were challenged with B16-OVA cells and followed up. ${ }^{* *} P<0.005$, t $P<0.0005$; Student's $t$ test. Data are representative of $3(\mathbf{E})$ or $2(\mathbf{F})$ experiments with 5 mice/group. assessed their activation and phenotypic profile 6 days after the infusion of OVA- or mock-GMLs from either WT or $\beta 2 \mathrm{~m}^{-/-}$mice (Figure 3D and data not shown). In both the experimental settings, FACS analysis of treated mice showed that OT-II T cells had undergone cell division, upregulation of CD44, and downmodulation of CD62L (Figure 3D). However, proliferation was less intense than that observed with OT-I CD8 ${ }^{+} \mathrm{T}$ cells.

To further confirm that the vaccination with OVA-GML endowed naive CD8 ${ }^{+} \mathrm{OT}$-I T cells with full effector functions capable of controlling tumor growth in vivo, we performed tumor challenge experiments in mice adoptively transferred with OT-I cells and vaccinated with GMLs. Forty-eight hours after the injection of $5 \times 10^{4}$ B16-OVA melanoma cells, mice were adoptively transferred with OT-I T cells and 24 hours later treated with OVA-GMLs. OT-I $\mathrm{T}$ cells do not spontaneously recognize the tumor; consequently, untreated animals failed to control its growth (data not shown).
Only the administration of OVA-GMLs was able to prime in vivo the naive $\mathrm{CD}^{+}$OT-I T cells, enabling mice to successfully control tumor growth (Figure 3E). The involvement of the above-described cross-presentation mechanism was also confirmed in this experimental setting by the administration of OVA-GMLs from $\beta 2 \mathrm{~m}^{-/-}$ mice that resulted in a comparable control of tumor growth (Figure $3 \mathrm{E})$. As expected, mock-GMLs were ineffective. These results were further confirmed when mice were challenged 40 days after OVA-GML vaccination (Figure 3F).

APCs responsible for in vivo T cell priming are bona fide DCs. To prove that DCs were playing a central role in eliciting $\mathrm{T}$ cell priming, we took advantage of CD11c-DTR transgenic mice. CD11c ${ }^{+}$DCs from these mice express the diphtheria toxin (DT) receptor, and therefore they can be conditionally deleted by administration of DT (26). CD11c-DTR mice were injected with $1.5 \times 10^{6}$ CFSElabeled OT-I CD8 ${ }^{+} \mathrm{T}$ cells. Eight hours later, mice were treated i.p. 

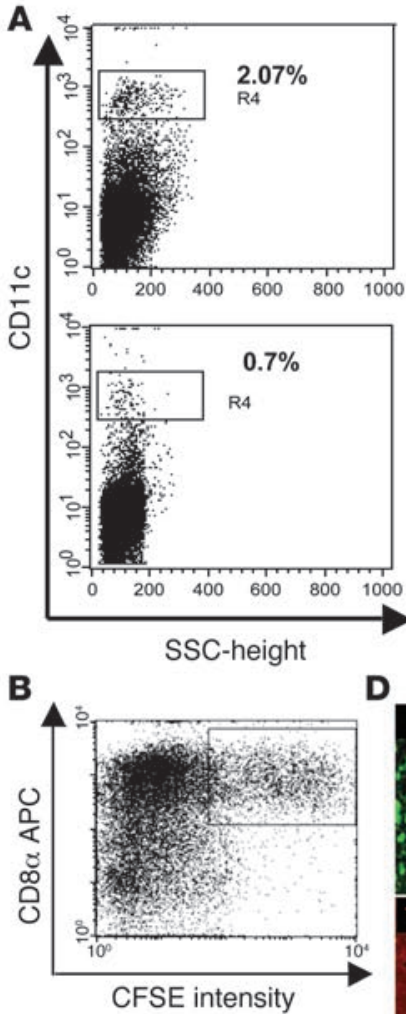

D
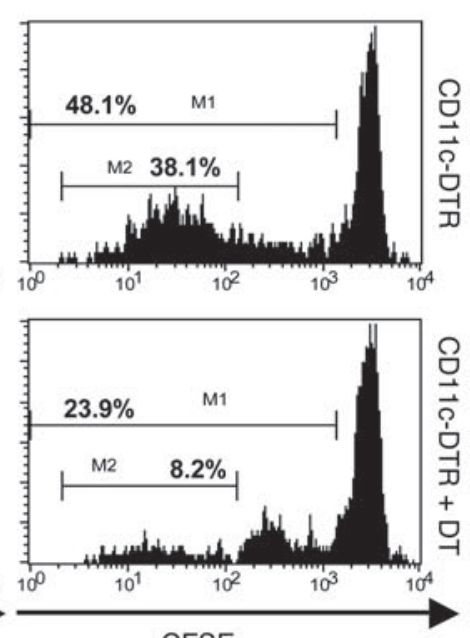

CFSE
C

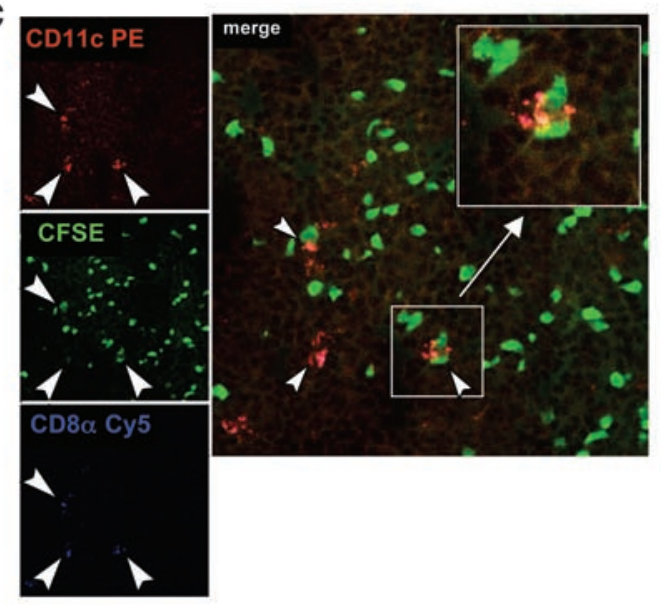

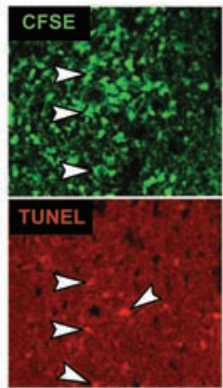
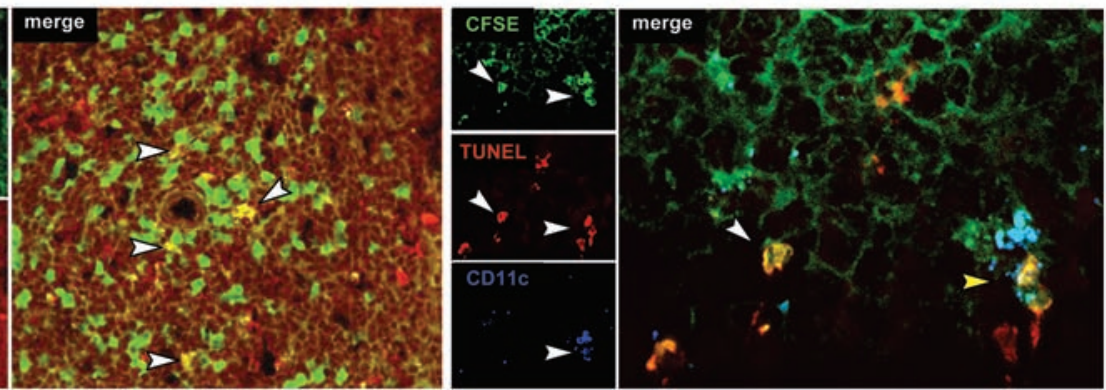

Figure 4

Analysis of OT-I proliferation in DC-depleted mice and characterization of phagocytosing DCs. (A) Purified OT-I T cells were labeled with CFSE and infused into CD11c-DTR mice left untreated or treated i.p. with $4 \mathrm{ng} / \mathrm{g}$ body weight DT. The day after, mice were given i.v. with $10 \times 10^{6}$ OVAGMLs from $32 \mathrm{~m}^{-/-}$mice. Seventy-two hours later, spleen and LNs were harvested and analyzed for OT-I proliferation and for the percentage of CD11C+ DCs present in SLOs. Histograms (CFSE dilution on CD45.1-gated OT-I T cells) show sustained OT-I proliferation in untreated CD11CDTR transgenic mice (48.1\%; upper-right panel) compared with that observed in DC-depleted mice (23.9\%; lower-right panel). The fraction of actively proliferating OT-I cells was remarkably different in the 2 groups of mice $(38.1 \%$ vs. $8.2 \%)$. Accordingly, we found $2.07 \%$ CD $11 \mathrm{C}^{+} \mathrm{DCs}$ in untreated CD11C-DTR transgenic mice and only $0.7 \%$ in the DC-depleted mice (left panels). Data are representative of 2 experiments performed on splenocytes of 2 mice/group. (B) CD11c-purified DCs from mice treated with CFSE-labeled OVA $\beta 2 \mathrm{~m}^{-/-}$GMLs were analyzed by FACS for CFSE uptake and CD8 $\alpha$ expression. Data are representative of 3 independent experiments. (C) Confocal microscopic analysis. CFSE-labeled GML are displayed as green staining. CD11c and CD8 $\alpha$ molecules (DCs) are visualized with CD11c-PE and CD8 $\alpha$-Cy 5 mAbs and displayed as red and blue staining, respectively. Arrowheads indicate CD11 $c^{+} C D 8 \alpha^{+} D C s$ engulfed by CFSE-labeled GMLs, shown at higher magnification in the inset. Original magnification, $\times 40$. (D) TUNEL + CFSE+ apoptotic GMLs (red and green staining, respectively) were detected in SLOs of treated mice (left panels, white arrowheads) and displayed as yellow staining in the optically merged confocal image (original magnification, $\times 40$ ). Right panels show apoptotic CFSE-labeled GMLs phagocytosed by SLO-resident CD11c DCs (blue staining). The white arrowhead indicates TUNEL ${ }^{+} \mathrm{CFSE}^{+} \mathrm{GML}$, whereas the yellow arrowhead shows a DC phagocytosing apoptotic bodies (triple staining; original magnification, $\times 63$ ).

with $4 \mathrm{ng} / \mathrm{g}$ body weight DT, and the day after they were given $10 \times 10^{6}$ OVA-GMLs. Spleen and LNs were harvested 72 hours after GML treatment and analyzed by FACS to evaluate OT-I proliferation and the presence of CD11 $\mathrm{c}^{+}$cells (Figure 4A). In untreated CD11c-DTR mice, we observed $38.1 \%$ of OT-I cells actively proliferating, whereas only $8.2 \%$ of OT-I cells showed some proliferation in CD11c-DTR mice treated with DT. The OT-I proliferation strongly correlated with the percentage of $\mathrm{CD} 11 \mathrm{c}^{+}$cells present in SLOs of DT-treated (0.7\%) and untreated (2.07\%) mice (Figure 4A, left panels). These results demonstrate that in our vaccination setting, priming of antigen-specific T cells is mediated by host DCs.

We then characterized the subset of SLO-resident APCs responsible for cross-presentation of GML-derived antigens. Twelve hours after the infusion of CFSE-labeled OVA-GMLs, approxi- mately $20 \%$ of the CD $11 c^{+} \mathrm{CD} 8 \alpha^{+}$DC subset in the spleen and LNs of treated mice expressed the CFSE dye (Figure 4B), with the percentage of $\mathrm{CD} 11 \mathrm{c}^{+} \mathrm{CD} 8 \alpha^{+} \mathrm{CFSE}^{+}$cells decreasing after 36 and 60 hours (data not shown). In contrast, only a minority $(3 \%-5 \%)$ of the $\mathrm{CD} 11 \mathrm{c}^{+} \mathrm{CD} 8 \alpha^{-}$population was taking up CFSE-labeled OVAGMLs (Figure 4B). The predominant role of the CD8 $\alpha^{+}$subset of CD11 $\mathrm{c}^{+}$DCs in the phagocytosis of cell-associated antigen (27) was confirmed by confocal microscopic analysis of serial sections of SLOs, where we frequently observed the colocalization of CFSE with CD $11 \mathrm{c}^{+} \mathrm{CD} 8 \alpha^{+}$DCs (Figure 4C).

To investigate whether antigenic material phagocytosed by DCs came from dying GMLs, we performed TUNEL assay on SLOs collected at different time points $(6,12$, and 24 hours) upon the infusion of CFSE-labeled GMLs. A relevant rate of apoptotic GMLs 

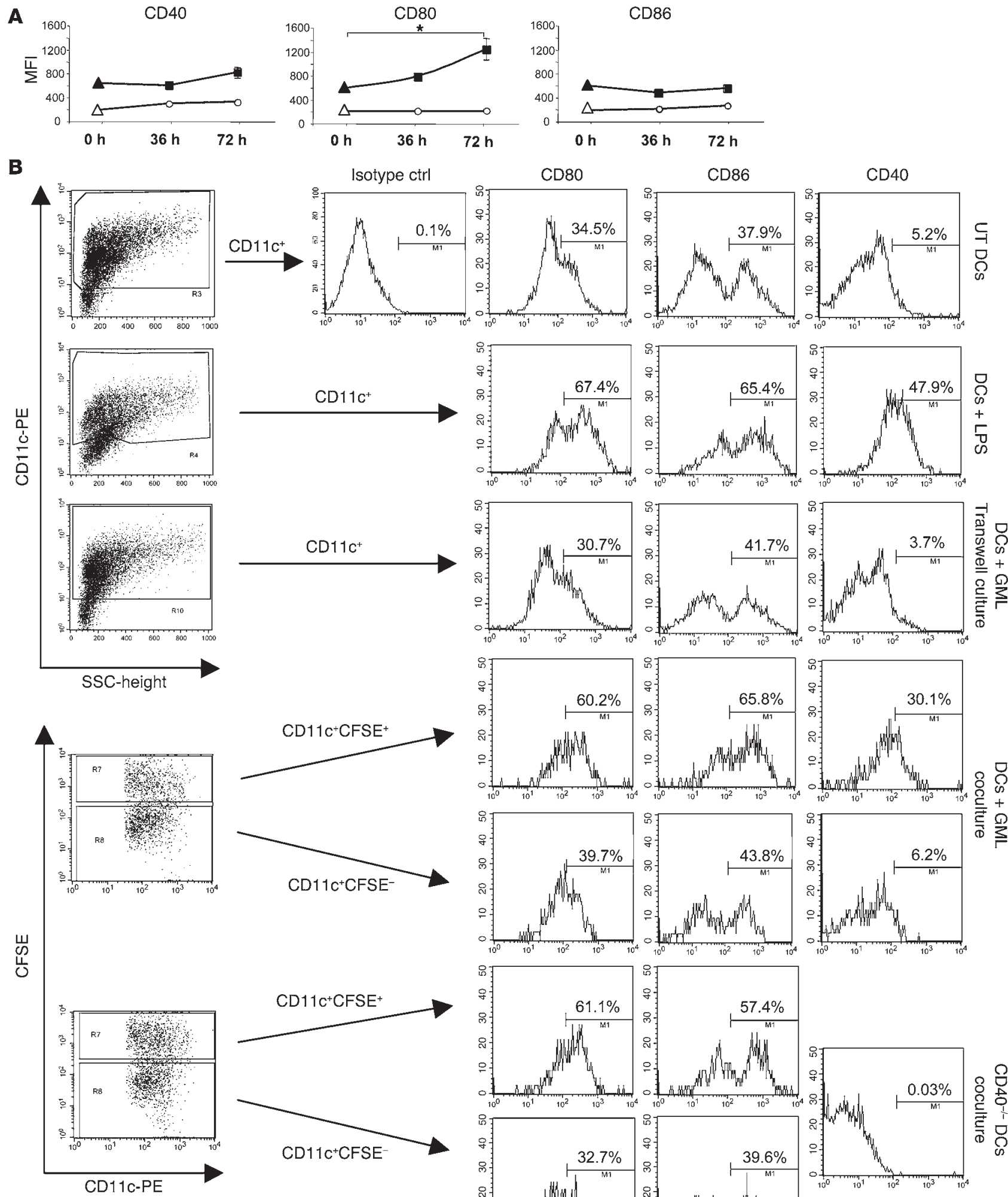

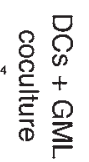
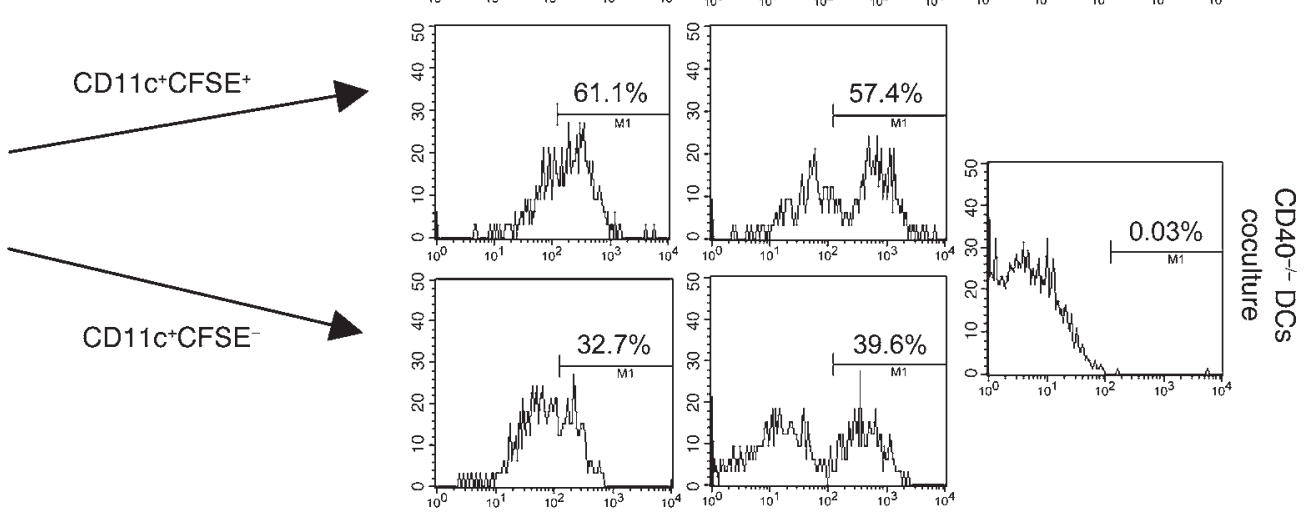


\section{Figure 5}

GMLs induce maturation of phagocytosing DCs in vivo and in vitro. (A) Thirty-six and 72 hours after CFSE-labeled GML infusion, DCs from SLOs of treated mice were purified and analyzed for CD40, CD80, and CD86 expression. The analysis was performed on $\mathrm{CD} 11 \mathrm{C}^{+} \mathrm{CD} 8 \alpha^{+} \mathrm{MHC}-\mathrm{II}^{\text {high }} \mathrm{DCs}$ (filled symbols) and CD11 $\mathrm{C}^{+} \mathrm{CD} 8 \alpha^{+} \mathrm{MHC}-\mathrm{II}^{+} \mathrm{DCs}$ (open symbols). Open circles and filled squares identify $\mathrm{CFSE}^{-}$nonphagocytosing and $\mathrm{CFSE}^{+}$phagocytosing DCs, respectively. DCs from untreated mice (0 hours) were also analyzed (triangles). ${ }^{*} P<0.05$, Student's $t$ test. MFI, mean fluorescence intensity. (B) DCs differentiated from bone marrow of B6 mice were left untreated, activated with LPS, cocultured with CFSE-labeled GMLs, or cultured with CFSE-labeled GMLs in Transwell plates. DCs from $\mathrm{CD} 40^{-/-}$mice were cocultured with CFSE-labeled GMLs. Fortyeight hours later, cells were analyzed by FACS for CD11c, CD80, CD86, and CD40 expression. In coculture conditions, the analysis

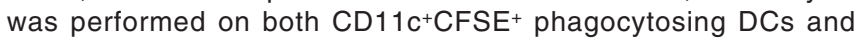
CD11 ${ }^{+} \mathrm{CFSE}^{-}$nonphagocytosing DCs. ctrl, control.

$\left(\mathrm{CFSE}^{+} \mathrm{TUNEL}^{+}\right)$was detected during the entire time of follow up (3.65\% at 6 hours, $2.2 \%$ and $4.4 \%$ at 12 and 24 hours, respectively), whereas only a few resident lymphocytes showed evidence of apoptosis (1.25\% of CFSE-TUNEL ${ }^{+}$cells), suggesting that GMLs, once they had reached SLOs, had undergone apoptosis (Figure 4D, left panel). Moreover, triple staining for DCs (with anti-CD11c mAb), GMLs (CFSE), and apoptotic cells (TUNEL) revealed the presence of apoptotic bodies engulfed by DCs (Figure 4D, right panel). Those phagocytosing DCs $\left(\mathrm{CD} 11 \mathrm{c}^{+} \mathrm{CD} 8 \alpha^{+} \mathrm{CFSE}^{+}\right)$belong to a well-characterized subset expressing CD205 (DEC-205), intermediate levels of CD11b, no CD4 (data not shown), and high levels of MHC-II (mean fluorescence intensity: 8,300) $(28,29)$.

Phagocytosing DCs undergo activation in vivo and in vitro by a cellto-cell contact mechanism independent of CD40 triggering. To determine the activation status of SLO-resident DCs, we performed a FACS analysis of phagocytosing $\left(\mathrm{CFSE}^{+}\right)$and nonphagocytosing

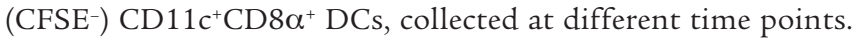
The analysis demonstrated that phagocytosing DCs belonged to the $\mathrm{CD} 11 \mathrm{c}^{+} \mathrm{CD} 8 \alpha^{+} \mathrm{MHC}-\mathrm{II}^{\text {high }}$ subset and showed an activated phenotype, as confirmed by late ( 72 hours after GML infusion) upregulation of the costimulatory molecules B7.1 (CD80, 72 hours versus 0 hours; $P<0.05$ ) and to a lesser extent CD40 (Figure 5A). We did not observe such activation in nonphagocytosing (CFSE $\left.{ }^{-}\right)$ DCs and in CD $11 \mathrm{c}^{+} \mathrm{CD} 8 \alpha^{+} \mathrm{MHC}-\mathrm{II}^{\text {high }}$ DCs from untreated mice (Figure 5A). To further investigate the mechanism responsible for such activation, we carried out in vitro coculture experiments on bone marrow-derived DCs (Figure 5B) and on CD11 $\mathrm{c}^{+}$DCs harvested from SLOs of naive mice (Supplemental Figure 2). Bone marrow-derived DCs were either left untreated, activated with LPS $(1 \mu \mathrm{g} / \mathrm{ml})$, cocultured with CFSE-labeled GMLs, or cultured with CFSE-labeled GMLs in transwell plates. After 24 (data not shown) and 48 hours, LPS-activated DCs upregulated CD80, CD86, and CD40, whereas untreated DCs did not (Figure 5B). Analysis of DCs cocultured with CFSE-labeled GMLs showed that only the phagocytosing (i.e., CD $11 \mathrm{c}^{+} \mathrm{CFSE}^{+}$) DCs had undergone activation, suggesting that DC activation would require cell-to-cell contacts. This hypothesis was then confirmed by experiments performed in the transwell culture system, which did not allow DC maturation by preventing direct DC-GML interactions (Figure 5B). Interestingly, DCs differentiated from CD $40^{-/-}$mice were activated upon coculture with CFSE-labeled GMLs, demonstrating that in our system, DC activation is independent of CD40/CD40L triggering. Similar results were obtained using the CD11 $\mathrm{c}^{+}$DCs harvested from SLOs of naive mice (Supplemental Figure 2).

Upon in vivo phagocytosis, DCs are able to activate naive T cells. To determine whether the above-characterized population was, indeed, responsible for antigen presentation, DCs isolated (95\%-98\% CD $11 \mathrm{c}^{+}$) from spleen and LNs of B6 mice 60 hours after the infusion of OVA-GMLs from $\beta 2 \mathrm{~m}^{-/}$mice were used to stimulate in vitro CFSE-labeled OT-I T cells. Both OVA-specific IFN- $\gamma$ release (Figure $6 \mathrm{~A}$, right panel) and proliferation (Figure $6 \mathrm{~A}$, left and right panels) were observed. As expected, there was neither IFN- $\gamma$ release nor proliferation of CD8 ${ }^{+}$OT-I cells incubated with DCs purified from mice treated with mock-transduced $\beta 2 m^{-/}$lymphocytes (Figure $6 \mathrm{~A}$ ), thus demonstrating that upon in vivo phagocytosis of GML, DCs are able to prime OVA-specific T cells.

TAA delivered by GMLs into SLOs of vaccinated mice persists up to 120 hours. Finally, we evaluated how long the delivered TAA persisted into SLOs of mice treated with the vaccination protocols used in the prophylactic and therapeutic tumor settings (i.e., i.v. infusion of OVA-GML from $\beta 2 \mathrm{~m}^{-/-}$mice or s.c. injection of peptidepulsed DCs). CD $11 \mathrm{c}^{+}$DCs were harvested from SLOs of mice at different times $(36,72$, and 120 hours) after the treatments and were cocultured with naive OT-I CD8 ${ }^{+} \mathrm{T}$ cells. Forty-eight hours later, IFN- $\gamma$ release was measured. Seventy-two hours after the treatments, DCs from OVA-GML-treated mice induced OT-I T cells to release approximately 2 -fold greater levels of IFN- $\gamma$ than DCs from mice treated with peptide-pulsed DCs $(1,869.1 \mathrm{pg} / \mathrm{ml}$ vs. 957.9). Notably, 120 hours later, only DCs from GML-treated mice were still able to activate OT-I T cells (IFN- $\gamma$ release: 197 $\mathrm{pg} / \mathrm{ml}$ ). These results along with data of GML persistence within SLOs (Figure 2A) indicate that GMLs provide SLO-resident DCs with a continuous source of antigen for longer time, resulting in a prolonged $\mathrm{T}$ cell activation.

\section{Discussion}

In this study we have investigated a novel approach for cancer vaccination, based on the in vivo delivery of TAAs directly to SLOs by GMLs. This approach could improve the current DC-based protocols (30), e.g., ex vivo selection and differentiation of the most appropriate DC subset (31), the low number of intradermally injected DCs reaching the draining LNs (32), and the limited halflife of MHC-I-peptide complexes on the DC cell surface (33). In our system, the GMLs constitutively express the antigen (i.e., TRP-2, OVA); therefore, there are no time constraints limiting their migration to SLOs or the transfer of the antigen to DCs. Indeed, up to 60-72 hours after injection of OVA-GMLs, DCs harvested from SLOs were able to produce maximum stimulation. Notably, DCs harvested 120 hours after OVA-GML infusion were still able to activate OVA-specific $\mathrm{CD}^{+} \mathrm{T}$ cells, whereas those from mice treated with peptide-pulsed DCs did not. These results indicate that DC targeting with TAA-GMLs could overcome some of the abovementioned limitations of the DC-based vaccines, particularly the low number of DCs reaching SLOs and the rapid degradation/loss of MHC-I-peptide complexes. Additionally, the constitutive and strong expression of the transgene products, driven by viral promoters, combined with the ability of GMLs to migrate to SLOs might make them similar to virus-infected cells, which produce enormous amounts of antigen within immunological priming sites (34).

This vaccination approach also elicited antigen-specific $\mathrm{CD}^{+} \mathrm{T}$ cells. However, the proliferation of the $\mathrm{CD} 4^{+} \mathrm{T}$ cell compartment was less sustained than that of the $\mathrm{CD}^{+} \mathrm{T}$ cells. This result is in 
A
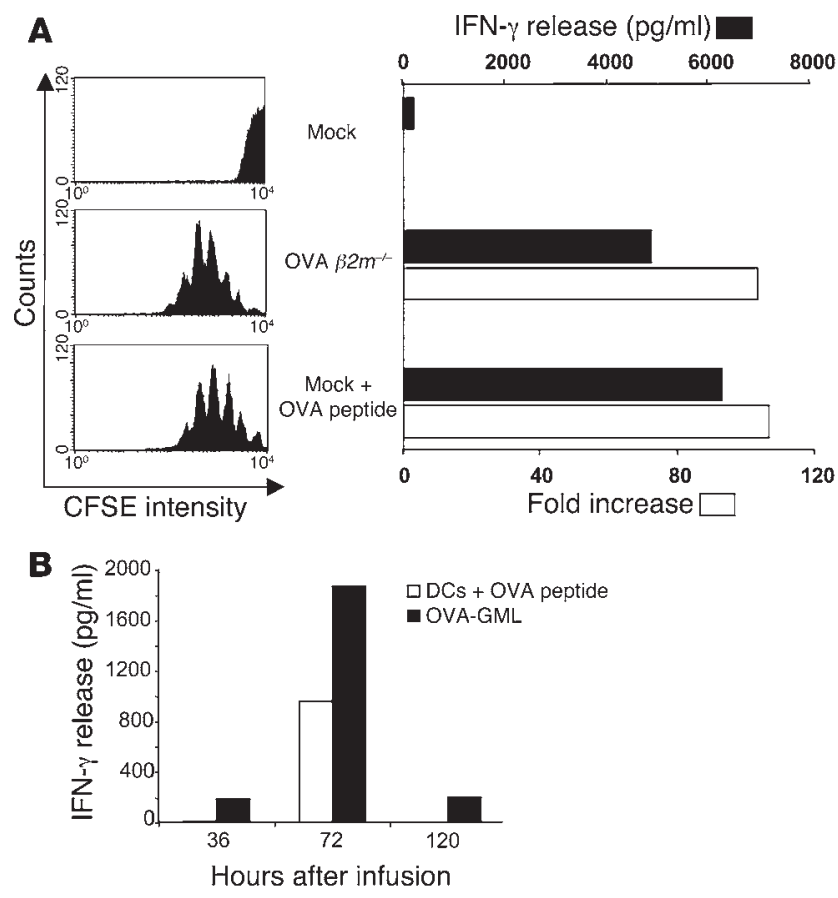

agreement with recent data (35) showing that MHC-I and -II antigen presentation is achieved by different DC subsets. In particular, the $\mathrm{CD} 11 \mathrm{c}^{+} \mathrm{CD} 8 \alpha^{+}$subset is responsible for MHC-I presentation, the $\mathrm{CD} 11 \mathrm{c}^{+} \mathrm{CD} 8 \alpha^{-}$subset for MHC-II presentation. In our setting we demonstrated (Figure 4) that the majority of the GML-associated antigen is taken up by the $\mathrm{CD} 11 \mathrm{c}^{+} \mathrm{CD} 8 \alpha^{+}$subset. Therefore, we hypothesize that the reduced proliferation of $\mathrm{CD}^{+} \mathrm{T}$ cells would reflect a lower recruitment of naive $T$ cells due to the limited uptake of GML-associated antigen by the CD $11 \mathrm{c}^{+} \mathrm{CD} 8 \alpha^{-}$subset $(3 \%-5 \%)$. However, in our vaccination setting, the reduced proliferation of TAA-specific $\mathrm{CD}^{+} \mathrm{T}$ cells did not dampen the development of an effective antitumor response in vivo. Moreover, in a pivotal clinical study using a similar strategy, we have observed the induction of fully active CD4+ effector cells specific for the TAA carried by GMLs (V. Russo et al., unpublished observations).

Mice vaccinated with TRP-2-GMLs were protected from a subsequent tumor challenge as well as those vaccinated with DCs ex vivo pulsed with TRP-2-derived peptides, thus suggesting a comparable efficacy of the 2 approaches. Notably, in a more stringent therapeutic tumor model, we observed a long-term survival benefit of TRP-2-GML vaccination. However, in our opinion, a more stringent and informative comparison between vaccination strategies based on ex vivo and in vivo DC loading could be addressed in humans. In this setting, the high degree of MHC-I/II polymorphisms would allow the full exploitation of the immunogenicity of the entire antigenic proteins and the in vivo processing and presentation capabilities of SLO-resident DCs.

In our murine model, an efficient uptake of antigenic material by LNs/spleen-resident DCs is able to induce the activation of TAAspecific responses. In agreement with other experimental models $(14,36)$, we show that the activation of naive TAA-specific T cells following the infusion of TAA-GMLs, involves the targeting/transfer of the antigen to a defined subset of CD $11 \mathrm{c}^{+} \mathrm{DCs}$ expressing the CD8 $\alpha$ molecule $(27,36,37)$ and requires the cross-presentation of the TAA $(38,39)$, as demonstrated by the treatment of mice with

\section{Figure 6}

In vitro cross-presentation of OVA-GMLs by CD11 $\mathrm{c}^{+} \mathrm{DCs}$ and kinetics of TAA persistence within SLOs of treated mice. (A) In vitro cross-presentation of OVA-GMLs by CD11 c+ DCs. Pure populations (95\%-98\%) of $\mathrm{CD} 11 \mathrm{c}^{+} \mathrm{DCs}$ from lymphoid organs of mice treated with mock- or OVA $\beta 2 \mathrm{~m}^{-/}$GMLs were challenged in vitro with highly purified CFSElabeled CD8 ${ }^{+}$OT-I T cells. Forty-eight hours later, supernatants were tested for IFN- $\gamma$ release (right panel, black bars). Cell proliferation, measured as CFSE dilution (left panel, CFSE intensity, ), was evaluated 4 days later. Increase in the absolute number of proliferating OT-I $T$ cells (Fold increase) is shown in the right panel (white bars). As positive control, OT-I T cells were stimulated with OVA $257-264-$ pulsed DCs (Mock + OVA peptide). (B) Pure populations (95\%-98\%) of $\mathrm{CD}_{11 \mathrm{C}^{+}} \mathrm{DC}$ s recovered from SLOs of mice sacrificed 36,72 , and 120 hours after treatment with OVA $\beta 2 m^{-/}$GMLs, OVA $257-264-$ pulsed DCs, or unpulsed DCs were challenged in vitro with CD8+ OT-I T cells as described above. Supernatants collected after 48 hours of coculture were tested for IFN- $\gamma$ release.

GMLs from $\beta 2 m^{-/-}$animals. The essential role of DCs was definitely confirmed by the loss of sustained TAA-specific proliferation in DC-depleted mice (i.e., CD11c-DTR mice). Different from studies carried out by other groups $(14,40)$, in our model the induction of TAA-specific effector cells was obtained without adding any further DC-activating stimulus. However, 72 hours after the treatment we observed an increased expression of activation markers (i.e., B7.1 and CD40) by phagocytosing DCs. These results were further confirmed by in vitro experiments with bone marrow-derived DCs and CD $11 c^{+}$DCs harvested from SLOs. Only phagocytosing DCs cocultured with GMLs were able to undergo maturation, indicating that DC activation would require cell-to-cell contacts. Moreover, the use of DCs from CD $40^{-/-}$mice allowed us to hypothesize that the DC activation could be induced by the GMLs via a direct interaction with DC-activating receptors other than CD40 (41).

Further genetic modifications of TAA-GMLs to express SLOhoming molecules, and the combined administration of TAAGMLs and ganciclovir to kill GMLs, could increase antigen availability and therefore improve the treatment.

In conclusion, transduced lymphocytes represent an efficient way for in vivo loading of TAAs on DCs and for the induction of effective antitumor responses.

\section{Methods}

Mice. B6 mice (8-10 weeks of age) were obtained from Harlan. B6 $\beta 2 \mathrm{~m}^{-/-}$ mice lack MHC class I expression (22). OT-I (Ly 5.1) mice (42) are transgenic for an $\alpha \beta$ TCR specific for the $\mathrm{H}-2 \mathrm{~K}^{\mathrm{b}}$-restricted $\mathrm{OVA}_{257-264}$ peptide. $\mathrm{B} 6 \mathrm{CD} 40^{-/-}$and CD11c-DTR/GFP (CD11c-DTR) mice were obtained from the Centre de Distribution, Typage \& Archivage animal, Institut de Transgénose. Mice were housed under pathogen-free conditions. Animal studies were approved by the Institutional Animal Care and Use Committee of the Scientific Institute H. San Raffaele.

Cell lines and reagents. The murine RMA lymphoma was kindly provided by $\mathrm{M}$. Bellone (Istituto Scientific Institute H. San Raffaele). The murine B16 melanoma cell line was purchased from ATCC. DT was purchased from Sigma-Aldrich and used as described by Jung et al. at $4 \mathrm{ng} / \mathrm{g}$ body weight (26).

Flow cytometry, confocal microscopy, and TUNEL assay. mAbs specific for murine markers were all from BD Biosciences - Pharmingen. Isotype controls from the same manufacturers were used. Before staining, cells were incubated with Fc Block (purified $\alpha$-CD 16/ $\alpha$-CD32 mAbs; BD Biosciences - Pharmingen). Samples were run on a FACSCalibur (BD) and analyzed 
by CellQuest software (BD). H2K $\mathrm{K}^{\mathrm{b}}$-SIINFEKL OVA pentamer-PE was from ProImmune. TUNEL was performed on SLOs from treated mice using the TUNEL TMR-dUTP assay (Roche) according to the manufacturer's recommendations. For confocal microscopy, B6 mice were injected with CFSElabeled (Molecular Probes; Invitrogen) OVA-transduced lymphocytes $\left(10 \times 10^{6}\right.$ to $\left.20 \times 10^{6}\right)$. Six, 12 , and 24 hours later, spleen and LNs (cervical, axillary, and inguinal) were collected and fixed in $4 \%$ paraformaldehyde (Sigma-Aldrich) for 2 hours at room temperature. Lymphoid organs were then washed in PBS and incubated with $30 \%$ saccharose overnight at room temperature, washed, embedded in Tissue-Tek OTC (Sakura Finetek), frozen in isopentane cooled by liquid nitrogen, and stored at $-20^{\circ} \mathrm{C}$ until use. Cryosections (10 $\mu \mathrm{m}$ thick) were adhered to poly-L-lysine-coated glass coverslips for 1 hour. Before staining, cryosections were treated with PBS containing $10 \% \mathrm{FCS}$ and rat $\operatorname{IgG}(50 \mu \mathrm{g} / \mathrm{ml})$ for 1 hour at room temperature and then incubated with rat anti-mouse $\mathrm{CD} 3-\mathrm{PE} \mathrm{mAb}(\mathrm{BD})$. To visualize DCs, we used CD11c-PE and CD8 $\alpha$-PE-Cy5 mAbs (BD).

Retroviral vectors and transduction procedures. The OVA-CSM and TRP-2CSM retroviral vectors were constructed as previously described (43), with OVA or the murine TRP- 2 under the control of the viral LTR. Expression of $\triangle$ LNGFr was driven by the Sv 40 promoter. Splenocytes $\left(5 \times 10^{6}\right.$ cells $\left./ \mathrm{ml}\right)$ from $\mathrm{B} 6$ or $\beta 2 \mathrm{~m}^{-/}$mice were stimulated in the presence of $100 \mathrm{U}$ of rhIL-2 (Proleukin; Chiron) and $5 \mu \mathrm{g} / \mathrm{ml}$ of concanavalin A (Sigma-Aldrich). Forty-eight hours later, splenocytes were transduced with virus-containing supernatant by 2 rounds of centrifugation (120 minutes, 1,200 g) a day apart, in the presence of $8 \mu \mathrm{g} / \mathrm{ml}$ of polybrene (Sigma-Aldrich). Three days later, splenocytes were analyzed for $\triangle \mathrm{LNGFr}$ expression and then expanded for 10-14 days. B16 murine melanoma cells were transduced with the OVA-CSM vector and selected for $\triangle$ LNGFr expression by magnetic beads (Dynabeads M-450; Dynal; Invitrogen) coated with the LNGFr-specific mAb 20.4 (ATCC).

Adoptive transfer, immunization experiments, and ex vivo recall assay. OT-I $\mathrm{CD}^{+} \mathrm{T}$ cells were enriched from spleen and LNs by depletion of $\mathrm{B}$ cells with Dynabeads Mouse pan B (B220) (Dynal; Invitrogen) and labeled with CFSE. Briefly, cells were incubated at $10 \times 10^{6}$ cells $/ \mathrm{ml}$ in CFSE at a final concentration of $4 \mu \mathrm{M}$ for 8 minutes at room temperature. The labeling reaction was stopped by adding the same volume of FCS. After washing, $3 \times 10^{6} \mathrm{CFSE}-1$ labeled $\mathrm{CD}^{+} \mathrm{T}$ cells/mouse were injected into the tail vein of sex-matched $\mathrm{B} 6$ recipients. After 24 hours recipients were treated i.v. with $4 \times 10^{6}$ GMLs. Splenocytes harvested 8 days after vaccination were restimulated in vitro (1:1 ratio) with syngeneic irradiated splenocytes, pulsed with $2 \mu \mathrm{g} / \mathrm{ml} \mathrm{OVA}_{257-264}$ peptide. Four days later, OT-I CD8 ${ }^{+} \mathrm{T}$ cells were purified by FACSVantage sorting (BD) using V $\alpha 2 / V \beta 5.1$-specific mAbs. OT-I $\mathrm{CD}^{+}$effectors $\left(1 \times 10^{4}\right)$ were then challenged with $2 \times 10^{4}$ RMA cells pulsed with OVA $257-264$. After 24 hours we measured IFN- $\gamma$ content in the supernatant by ELISA assay (BD Biosciences - Pharmingen) according to the manufacturer's recommendations. IFN- $\gamma$ released on unpulsed RMA cells was always subtracted. OT-II CD4 ${ }^{+} \mathrm{T}$ cells were purified with the $\mathrm{CD} 4^{+}$ $\mathrm{T}$ cell isolation kit (Miltenyi Biotec) and labeled with CFSE as described for OT-I CD8 ${ }^{+} \mathrm{T}$ cells. CFSE-labeled $\mathrm{CD}^{+} \mathrm{T}$ cells $\left(3 \times 10^{6}\right)$ were injected into the tail vein of sex-matched $\mathrm{B} 6$ recipients. After 24 hours recipients were treated i.v. with $4 \times 10^{6}$ or $10 \times 10^{6} \mathrm{GMLs}$. For the induction of OVAspecific endogenous repertoire experiments, B6 mice were treated 3 times at 2-week intervals with OVA-GMLs $\left(4 \times 10^{6}\right)$ and DCs $\left(3 \times 10^{5}\right.$ to $\left.5 \times 10^{5}\right)$ activated with LPS $(1 \mu \mathrm{g} / \mathrm{ml})$ and pulsed with $2 \mu \mathrm{g} / \mathrm{ml} \mathrm{OVA} 257-264$ peptide. Forty days later, spleen and LNs were collected, digested, washed, and then stained with the $\mathrm{H} 2 \mathrm{~K}^{\mathrm{b}}$-SIINFEKL OVA pentamer-PE together with mAbs specific for activation and memory murine markers.

In vitro cytotoxicity assay. Splenocytes from vaccinated mice $\left(3 \times 10^{6} / \mathrm{ml}\right)$ were cultured with $0.5 \mu \mathrm{M}$ TRP- 2 peptides. After 6 days, activated T cells were isolated on a Lympholyte-M gradient (Cedarlane Laboratories Ltd.) cultured 1 day in the presence of $20 \mathrm{IU} / \mathrm{ml} \mathrm{hrIL-2}$. Responder cells were then tested for cytolytic activity in a standard 4 -hour ${ }^{51} \mathrm{Cr}$ release assay. Data are mean $\pm \mathrm{SD}$ of experiments performed in triplicate of the percentage of specific lysis at the indicated $\mathrm{E} / \mathrm{T}$ ratios.

Ex vivo cross-presentation assay and kinetic of TAA persistence within SLOs. $\mathrm{CD} 11 \mathrm{c}^{+} \mathrm{DCs}$ were purified from $\mathrm{B} 6$ mice after vaccination with OVA-transduced $\beta 2 m^{-1-}$ lymphocytes $\left(10 \times 10^{6}\right.$ to $\left.20 \times 10^{6}\right)$. Spleen and LNs were digested for 40 minutes at $37^{\circ} \mathrm{C}$ with $0.5 \mathrm{mg} / \mathrm{ml}$ collagenase $\mathrm{A}, \mathrm{B}$, and D (Roche Diagnostics) and then resuspended in PBS containing 0.5\% BSA, $2 \mathrm{mM}$ EDTA, to disrupt T cell-DC complexes. Purification of DCs (92\%-98\% purity) was performed with rat anti-mouse CD11c mAb (N418)-coupled magnetic MicroBeads on miniMACS columns (Miltenyi Biotec). Purified DCs $\left(1.5 \times 10^{5}\right)$ were used as stimulators, whereas OT-I CD8 ${ }^{+} \mathrm{T}$ cells $\left(1.5 \times 10^{5}\right)$, isolated from LNs of transgenic mice by depletion using PEconjugated B220, CD11c, CD11b, CD4 mAbs followed by anti-PE MicroBeads incubation, were labeled with $3 \mu \mathrm{M}$ CFSE and used as responders. Experiments were performed in triplicates in 96-well U-bottom plates. As positive control, DCs from mice receiving mock-transduced $\beta 2 \mathrm{~m}^{-/-}$lymphocytes were pulsed with $2 \mu \mathrm{g} / \mathrm{ml}$ of OVA $257-264$ peptide. Forty-eight hours later, supernatants were tested for IFN- $\gamma$ production by ELISA. Two days later, the cells were counted and stained with rat anti-mouse CD3-FITC, CD45.1-PE, and CD8 $\alpha$-Cy-Chrome mAbs and analyzed by FACS, to evaluate OT-I CD8 ${ }^{+} \mathrm{T}$ cell-specific proliferation as a measure of CSFE dilution. For kinetic experiments of TAA persistence into SLOs, mice were treated i.v. with OVA-GMLs $\left(10 \times 10^{6}\right.$ to $\left.20 \times 10^{6}\right)$ from $\beta 2 \mathrm{~m}^{-/-}$mice or with DCs $\left(0.5 \times 10^{6}\right)$ pulsed with $2 \mu \mathrm{g} / \mathrm{ml}$ of $\mathrm{OVA}_{257-264}$ peptide and injected s.c. Thirty-six, 72, and 120 hours after treatments, DCs $\left(1.5 \times 10^{5}\right)$ purified as described above were used as stimulators, whereas purified OT-I CD8 ${ }^{+} \mathrm{T}$ cells $\left(1.5 \times 10^{5}\right)$, labeled with $3 \mu \mathrm{M}$ CFSE, were used as responders. Experiments were performed in triplicate in 96-well U-bottom plates. Forty-eight hours later, supernatants were tested for IFN- $\gamma$ production by ELISA. IFN- $\gamma$ released by responders and/or stimulators alone was always subtracted.

In vitro $D C$ activation assay. $\mathrm{CD} 11 \mathrm{c}^{+} \mathrm{DCs}$ were purified from $\mathrm{B} 6$ mice with rat anti-mouse $\mathrm{CD} 11 \mathrm{c}$ mAb (N418)-coupled magnetic MicroBeads on miniMACS columns (Miltenyi Biotec) (92\%-98\% purity) or differentiated from bone marrow, as described by Camporeale et al. (44).

Purified DCs $\left(3 \times 10^{5}\right)$ were left untreated, activated with LPS $(1 \mu \mathrm{g} / \mathrm{ml})$, cultured with CFSE-labeled GMLs in coculture or in transwell plates. Twenty-four hours later and 48 hours later, cells were harvested, washed once, and then stained with mAbs specific for murine CD3, CD11c, CD8 $\alpha$, CD80, CD86, and CD40.

In vivo experiments of $D C$ depletion. $C D 11 c-D T R$ mice were injected with $1.5 \times 10^{6}$ CFSE-labeled OT-I CD8 ${ }^{+} \mathrm{T}$ cells. OT-I T cells were purified and labeled with CFSE as described above. Eight hours later, mice were treated i.p. with $4 \mathrm{ng} / \mathrm{g}$ body weight DT. The day after, adoptively transferred mice were given $10 \times 10^{6}$ OVA-GMLs. Spleen and LNs were harvested 72 hours after GML treatment, processed, and analyzed by FACS to evaluate OT-I proliferation and the percentage of $\mathrm{CD} 11 \mathrm{c}^{+} \mathrm{DCs}$. The proliferation of OT-I $\mathrm{T}$ cells (CD45.1 $1^{+} \mathrm{T}$ cells) was evaluated as CFSE dilution.

In vivo antitumor response against B16 or B16-OVA melanomas. B6 mice were vaccinated i.v. 3 times at 2 -week intervals with either $4 \times 10^{6} \mathrm{TRP}-2$-transduced lymphocytes from WT and $\beta 2 \mathrm{~m}^{-/-}$mice; or with LPS-activated DCs $\left(5 \times 10^{5}\right.$ to $10 \times 10^{5}$ cells) generated as described by Camporeale et al. (44) and pulsed with $2 \mu \mathrm{g} / \mathrm{ml}$ of TRP- $2_{181-188}$ (VYDFFVWL) (19) and TRP- $2_{180-188}$ (SVYDFFVWL) (21) peptides. Two weeks or 40 days after the last vaccination, mice were inoculated s.c. with $5 \times 10^{4} \mathrm{~B} 16$ cells. Tumor size was evaluated by measuring perpendicular diameters by a caliper. For curative experiments mice were inoculated s.c. with $5 \times 10^{4} \mathrm{~B} 16$ cells. Seventy-two hours later, when the tumor area was approximately $20 \mathrm{~mm}^{3}$, mice were randomly assigned to 1 of the following treatments: (a) 3 injections of $4 \times 10^{6}$ 
mock-GMLs $(n=7)$, (b) $4 \times 10^{6}(n=9)$ or (c) $10 \times 10^{6}$ TRP-2-GMLs from $\beta 2 \mathrm{~m}^{-/-}$mice $(n=9)$ ), or (d) 3 injections of $5 \times 10^{5}$ LPS-activated DCs pulsed with $2 \mu \mathrm{g} / \mathrm{ml}$ of TRP- $2_{181-188}$ and TRP- $2_{180-188}(n=9)$. The treatments were administered 3 times at 7 -day intervals. Results were evaluated by comparing survival curves by log-rank test. Mice were adoptively transferred with $3 \times 10^{6}$ OT-I CD8 ${ }^{+} \mathrm{T}$ cells and after 24 hours vaccinated i.v. with $4 \times 10^{6}$ OVA-transduced lymphocytes from WT or $\beta 2 \mathrm{~m}^{-/-}$mice. B16-OVA cells $\left(5 \times 10^{4}\right)$ were injected s.c. either 48 hours before OT-I infusion for therapeutic experiments or 40 days after vaccination for protection experiments. Data are reported as the average tumor volume \pm SD.

Statistics. Statistical significance $(P<0.05)$ was determined by 2 -tailed Student's $t$ test and by the log-rank test.

\section{Acknowledgments}

We thank M. Bellone, M.P. Protti, A. Manfredi, A. Mondino, and P. Dellabona (Cancer Immunotherapy and Gene Therapy Program)

for discussions and critical comments. Additionally, we thank D. Dunlap and C. Panzeri (Advanced Light and Electron Microscopy Bio-Imaging Center [ALEMBIC]) for confocal microscopy analysis. This study was supported by the Italian Association for Cancer Research (AIRC).

Received for publication October 10, 2006, and accepted in revised form June 26, 2007.

Address correspondence to: Claudio Bordignon, Università Vita-Salute San Raffaele, Via Olgettina 58, 20132 Milan, Italy. Phone: 39-02-26432351; Fax: 39-02-26432285; E-mail: claudio.bordignon@hsr.it.

Vincenzo Russo and Arcadi Cipponi contributed equally to this work.

1. Van Der Bruggen, P., et al. 2002. Tumor-specific shared antigenic peptides recognized by human $\mathrm{T}$ cells. Immunol. Rev. 188:51-64.

2. Banchereau, J., and Steinman, R.M. 1998. Dendritic cells and the control of immunity. Nature. 392:245-252.

3. Dunn, G.P., Old, L.J., and Schreiber, R.D. 2004. The immunobiology of cancer immunosurveillance and immunoediting. Immunity. 21:137-148.

4. Childs, R., et al. 2000. Regression of metastatic renal-cell carcinoma after nonmyeloablative allogeneic peripheral-blood stem-cell transplantation. N. Engl. J. Med. 343:750-758

5. Dudley, M.E., et al. 2002. Cancer regression and autoimmunity in patients after clonal repopulation with antitumor lymphocytes. Science. 298:850-854.

6. Bonini, C., et al. 1997. HSV-TK gene transfer into donor lymphocytes for control of allogeneic graftversus-leukemia. Science. 276:1719-1724

7. Kolb, H.J., Schmid, C., Barrett, A.J., and Schendel, D.J. 2004. Graft-versus-leukemia reactions in allogeneic chimeras. Blood. 103:767-776.

8. Rosenberg, S.A., Yang, J.C., and Restifo, N.P. 2004. Cancer immunotherapy: moving beyond current vaccines. Nat. Med. 10:909-915.

9. Gabrilovich, D. 2004. Mechanisms and functional significance of tumour-induced dendritic-cell defects. Nat. Rev. Immunol. 4:941-952.

10. Wang, H.Y., et al. 2004. Tumor-specific human $\mathrm{CD} 4+$ regulatory $\mathrm{T}$ cells and their ligands: implications for immunotherapy. Immunity. 20:107-118.

11. Khong, H.T., and Restifo, N.P. 2002. Natural selection of tumor variants in the generation of "tumor escape" phenotypes. Nat. Immunol. 3:999-1005.

12. Allan, R.S., et al. 2003. Epidermal viral immunity induced by CD8alpha+ dendritic cells but not by Langerhans cells. Science. 301:1925-1928.

13. Tacken, P.J., et al. 2005. Effective induction of naive and recall $\mathrm{T}$-cell responses by targeting antigen to human dendritic cells via a humanized anti-DCSIGN antibody. Blood. 106:1278-1285.

14. Bonifaz, L.C., et al. 2004. In vivo targeting of antigens to maturing dendritic cells via the DEC-205 receptor improves T cell vaccination. J. Exp. Med. 199:815-824.

15. Iezzi, G., Scheidegger, D., and Lanzavecchia, A. 2001. Migration and function of antigen-primed nonpolarized T lymphocytes in vivo. J. Exp. Med. 193:987-993.

16. Gagliardi, M.C., et al. 1995. Presentation of peptides by cultured monocytes or activated $\mathrm{T}$ cells allows specific priming of human cytotoxic T lym- phocytes in vitro. Int. Immunol. 7:1741-1752.

17. Berger, C., Flowers, M.E., Warren, E.H., and Riddell, S.R. 2006. Analysis of transgene-specific immune responses that limit the in vivo persistence of adoptively transferred HSV-TK-modified donor T cells after allogeneic hematopoietic cell transplantation. Blood. 107:2294-2302.

18. Traversari, C., et al. 2007. The potential immunogenicity of the TK suicide gene does not prevent full clinical benefit associated with the use of TKtransduced donor lymphocytes in HSCT for hematologic malignancies. Blood. 109:4708-4715.

19. Bloom, M.B., et al. 1997. Identification of tyrosinase-related protein 2 as a tumor rejection antigen for the B16 melanoma. J. Exp. Med. 185:453-459.

20. Mavilio, F., et al. 1994. Peripheral blood lymphocytes as target cells of retroviral vector-mediated gene transfer. Blood. 83:1988-1997.

21. Parkhurst, M.R., et al. 1998. Identification of a shared HLA-A*0201-restricted T-cell epitope from the melanoma antigen tyrosinase-related protein 2 (TRP2). Cancer Res. 58:4895-4901.

22. Koller, B.H., Marrack, P., Kappler, J.W., and Smithies, O. 1990. Normal development of mice deficient in beta $2 \mathrm{M}, \mathrm{MHC}$ class I proteins, and CD8+ T cells. Science. 248:1227-1230.

23. Fu, Y.X., and Chaplin, D.D. 1999. Development and maturation of secondary lymphoid tissues. Annu. Rev. Immunol. 17:399-433.

24. Chao, C.C., Jensen, R., and Dailey, M.O. 1997. Mechanisms of L-selectin regulation by activated T cells. J. Immunol. 159:1686-1694.

25. Steinman, R.M., Hawiger, D., and Nussenzweig, M.C. 2003. Tolerogenic dendritic cells. Annu. Rev. Immunol. 21:685-711.

26. Jung, S., et al. 2002. In vivo depletion of CD11c(+) dendritic cells abrogates priming of CD8(+) T cells by exogenous cell-associated antigens. Immunity. 17:211-220.

27. den Haan, J.M., Lehar, S.M., and Bevan, M.J. 2000. CD8(+) but not CD8(-) dendritic cells cross-prime cytotoxic T cells in vivo. J. Exp. Med. 192:1685-1696.

28. Valdez, Y., et al. 2002. Major histocompatibility complex class II presentation of cell-associated antigen is mediated by CD8alpha+ dendritic cells in vivo. J. Exp. Med. 195:683-694.

29. Ohl, L., et al. 2004. CCR7 governs skin dendritic cell migration under inflammatory and steadystate conditions. Immunity. 21:279-288.

30. Schuler, G., Schuler-Thurner, B., and Steinman, R.M. 2003. The use of dendritic cells in cancer immunotherapy. Curr. Opin. Immunol. 15:138-147.

31. Schadendorf, D., et al. 2006. Dacarbazine (DTIC) versus vaccination with autologous peptide-pulsed dendritic cells (DC) in first-line treatment of patients with metastatic melanoma: a randomized phase III trial of the DC study group of the DeCOG. Ann. Oncol. 17:563-570.

32. De Vries, I.J., et al. 2003. Effective migration of antigen-pulsed dendritic cells to lymph nodes in melanoma patients is determined by their maturation state. Cancer Res. 63:12-17.

33. Ludewig, B., et al. 2001. Rapid peptide turnover and inefficient presentation of exogenous antigen critically limit the activation of self-reactive CTL by dendritic cells. J. Immunol. 166:3678-3687.

34. Zinkernagel, R.M. 2003. On natural and artificial vaccinations. Annu. Rev. Immunol. 21:515-546.

35. Dudziak, D., et al. 2007. Differential antigen processing by dendritic cell subsets in vivo. Science. 315:107-111.

36. Iyoda, T., et al. 2002. The CD8+ dendritic cell subset selectively endocytoses dying cells in culture and in vivo. J. Exp. Med. 195:1289-1302.

37. Schnorrer, P., et al. 2006. The dominant role of $\mathrm{CD} 8+$ dendritic cells in cross-presentation is not dictated by antigen capture. Proc. Natl. Acad. Sci. U. S. A. 103:10729-10734.

38. Bevan, M.J. 1976. Cross-priming for a secondary cytotoxic response to minor $\mathrm{H}$ antigens with $\mathrm{H}-2$ congenic cells which do not cross-react in the cytotoxic assay. J. Exp. Med. 143:1283-1288.

39. Heath, W.R., et al. 2004. Cross-presentation, dendritic cell subsets, and the generation of immunity to cellular antigens. Immunol. Rev. 199:9-26.

40. Liu, K., et al. 2002. Immune tolerance after delivery of dying cells to dendritic cells in situ. J. Exp. Med. 196:1091-1097.

41. Watts, T.H. 2005. TNF/TNFR family members in costimulation of T cell responses. Annu. Rev. Immunol. 23:23-68.

42. Hogquist, K.A., et al. 1994. T cell receptor antagonist peptides induce positive selection. Cell. 76:17-27.

43. Verzeletti, S., et al. 1998. Herpes simplex virus thymidine kinase gene transfer for controlled graftversus-host disease and graft-versus-leukemia: clinical follow-up and improved new vectors. Hum. Gene Ther. 9:2243-2251.

44. Camporeale, A., et al. 2003. Critical impact of the kinetics of dendritic cells activation on the in vivo induction of tumor-specific T lymphocytes. Cancer Res. 63:3688-3694. 